tried to offer a bribe to me before) and this relapse-two; inadequate response to treatrather frightened me. The drug companies ment-seven.

should inform their representatives that there is a difference between seduction and rape. Does this sort of thing happen often or do I look particularly corruptible? - I am, etc.,

Inkpen, Berks

Vernon Coleman

\section{Fluphenazine Injections: Adverse Effects and Treatment Failures}

SIR,-I wish to describe the adverse effects and treatment failures encountered during attempts to manage 70 schizophrenic patients with injections of fluphenazine enanthate or decanoate during the past five years. After initial stabilization, usually in hospital, injections were given three weekly in 38 cases, fortnightly in 24 cases, and four weekly in eight cases. All except five patients have received $25 \mathrm{mg}$ of fluphenazine at each injection; four received $12.5 \mathrm{mg}$, and one $37.5 \mathrm{mg}$. In addition, oral tranquillizers were prescribed for 36 patients and 56 patients were given routine anti-Parkinson drugs, usually orphenadrine.

The present survey has not revealed any straightforward relation between treatmen and depression. In five cases treatment had to be stopped because of depression. In four cases this was sustained and it followed each injection in one; three improved spontaneously and two recovered during courses of electroplexy. Four of these patients were receiving decanoate; seven patients who appear to have responded well to treatment have suffered mild depressive episodes; four responded to tricyclic antidepressives, one to electroplexy, one to a reduction in injection frequency, and one improved spontaneously.

There was one patient suffering from typical paranoid schizophrenia in whom depression appeared when fluphenazine treatment was interrupted and remitted when fluphenazine was resumed.

Two patients committed suicide. One was a 29-year-old man who was improving on three weekly injections, but who became depressed after accidentally missing an injection. He improved when treatment was resumed, but again missed an injection and killed himself shortly afterwards.

Estimates of the incidence of extrapyramidal side effects vary considerably. We probably gave routine anti-Parkinson drugs more frequently than was strictly necessary, in an effort to ensure that these difficult and often initially uncooperative patients were given no reason for stopping treatment.

In three cases treatment had to be stopped as a result of severe extrapyramidal side effects which did not respond adequately to the usual remedies. Eleven other patients showed moderately severe extrapyramidal side effects which did not lead to cessation of treatment. Only two of them admitted any awareness of these effects.

Treatment had to be stopped in five other cases, for the following reasons: lack of cooperation-two; excessive drowsiness-2; persistent vomiting of undetermined cause $\rightarrow$ one. In addition to the 13 patients whose traetment had to be stopped, nine other cases have been classified as therapeutic failures for the following reasons: psychotic
The remaining 46 patients appear to have done well, with obvious remission of symptoms and much less time in hospital since fluphenazine injections were started. They have now been treated for periods ranging from 18 months to over five years. As a result of fashionable efforts to keep patients out of hospital at practically any cost time spent in hospital no longer mirrors the duration and severity of mental illness as accurately as it used to. Nevertheless, it is interesting to note that for this group of 46 patients the total time interval between the onset of illness and the start of fluphenazine injections amounts to 434 patient-years, $15.6 \%$ of which were spent in hospital; 145 patient-years have elapsed since then, $3.3 \%$ of which have been spent in hospital.

Obviously, the results of a retrospective study must be interpreted very cautiously. However, it is worth noting that nine of the 11 patients who suffered adverse effects leading to the interruption of treatment were receiving fluphenazine decanoate. The other therapeutic failures were divided almost equally between the two drugs, as were the apparent successes. Most of the latter are paranoid schizophrenics with fairly well preserved personalities, who have proved to be unreliable pill takers-that is, a small subcarry a fairly good prognosis. The seven classed as "inadequate response to treatment" were almost certainly fairly reliable pill takers who had shown an inadequate response to oral medication; four of them showed quite severe personality deterioration

These findings suggest that although fluphenazine injections are a valuable addition to present methods of treatment, their benefit will be mainly felt by those patients with moderately severe illness who alone appear to have benefited from advances in treatment during the past 30 years. The hard core of more severely ill patients is likely to remain unaffected, and the problems associated with long-term medication will grow even greater.

I would like to thank Dr. M. C. Moss who allowed me to include some of his patients in this survey, and the nursing staff of the Ashfield Clinic, whose co-operation made it possible.

-I am, etc.

Ashfield Clinic,

Sutton in Ashfield, Notts

G. O. Dubourg

\section{Title for Anaesthetists}

SIR,-The proposed formation of a College of Anaesthetists leads me to suggest that the time has come to alter the name of the specialty, avoiding the American word "anesthesiology," which has never rung true to most British ears even though it has been adopted by the World Federation. This is not an original thought as the name "Clinical Physiology" has been put forward

in the past. I am not agreeing that this a modern department of anaesthesia, and perhaps something like "Physician in charge of Clinical Physiology and Resuscitation," even though cumbersome, would be a more apt title than "Anaesthetist."

History tells of the prolonged argument section of a class of patients who already name is an ideal description of the work of of last century over what name should be given to the discoveries of Crawford Long, Morton, Wells, and Simpson. This argument was won by the American Wendell Holmes, who coined the word "anaesthesia." I appeal for a British genius to find one all-embracing word to add to our language.-I am, etc.,

London W.4

Donald BLatchley

\section{Anaesthesia by Acupuncture}

SIR,-I was intrigued to read the report of Dr. S. G. Hamilton and others (5 August p. 352) of operations performed under acupuncture anaesthesia. In particular the description of a pneumonectomy performed with one needle inserted in the deltoid muscle. Does this mean that the basic problems ${ }^{1}$ of an open chest and collapsed lung have been overcome by acupuncture? I would be grateful to hear more details of this procedure.-I am, etc.,

Michael A. E. Ramsay

Anaesthetic Department
The London Hospital,

London E.1

1 Thoracic Anaesthesia, ed. W. W. Mushin, p. 1. Oxford, Blackwell, 1963.

\section{Coalworkers' Pneumoconiosis}

SIR,-We agree with Professor I. T. T. Higgins (17 June, p. 713), "that neither ventilatory lung function nor emphysema is related to $x$-ray category of simple pneumoconiosis in Glamorgan." We have said that there is little correlation between pulmonary function tests and radiological categories of $x$-ray in simple pneumoconiosis and we repeated in our article (18 March, p. 713) that "these reductions [in pulmonary function] are not related to category of simple pneumoconiosis." We agree with Rossiter ${ }^{2}$ that numerical radiological category is well related to the dust content of the lungs after death. We would therefore expect poor correlation between the dust content and pulmonary function. But the postmortem dust content is not necessarily a measure of the cumulative exposure of dust during life, nor of the pathological damage to the lungs caused by dust.

We agree with Cochrane and Higgins ${ }^{3}$ that there is no sound evidence to suggest an association of decreasing ventilatory function with increasing category of simple pneumoconiosis. As our study was based on miners who subsequently died in a defined area and theirs on random samples of living subjects drawn from defined populations we were reassured at this essential agreement. They continued: "there seems to be evidence for some decrease in ventilatory function in elderly miners . . . unrelated to dust retention as seen in the radiograph." We find a similar decrease at all ages, which we suggest is due to emphysema which they could not measure in living subjects.

We followed Dr. C. M. Fletcher's advice (8 July, p. 116) and expressed mean emphysema counts in relation to median (not mean) category of films read independently by two or more observers (highly experienced) on two or more occasions. We found, and reported in our article, a poor correlation. In 